\title{
PERANCANGAN MEDIA PEMBELAJARAN UNTUK DISEMINASI TEKNOLOGI PERTANIAN PEKARANGAN BERBASIS MULTIMEDIA INTERAKTIF DI BPTP JAWA TENGAH
}

\author{
Ahmad Zainudin', Daniel Rudjiono ${ }^{2}$, Rizki Sidik Wicaksono ${ }^{3}$ \\ ${ }^{1}$ Universitas STEKOM \\ Jl.Majapahit 605, e-mail:zaenudin @ stekom.ac.id \\ ${ }^{2}$ Universitas STEKOM \\ Jl.Majapahit 605, e-mail:danielrudjiono@gmail.com \\ ${ }^{3}$ Universitas STEKOM \\ Jl.Majapahit 605, e-mail:riskywicaksono21@gmail.com
}

\section{ARTICLE INFO}

Article history:

Received 30 Juni 2021

Received in revised form 5 Juli 2021

Accepted 31 Agustus 2021

Available online

\section{ABSTRACT}

Socialization of agricultural innovation and technology (inotek) in the yard has received great attention from the Kementerian Pertanian, with the aim of increasing food production and public access to food, as well as being a social safety net during the Covid-19 pandemic. Since 2017 BPTP Jawa Tengah has developed Taman Agro Inovasi which contains displays of various agricultural inotek in the yard, to serve as a place of learning for activists and agricultural actors in the yard. This study aims to create interactive multimedia to assist activists and potential users in learning the inotek of yard agriculture displayed at the Taman Agro Inovasi without having to visit the site directly. The research begins with extracting data and information about yard agricultural inotek which is displayed at Taman Agro Inovasi, followed by multimedia design, multimedia project creation, validation by supervisors and experts, and multimedia feasibility testing. Based on the validation results from media experts, material experts and target users, it shows that the multimedia products produced are very feasible to be used and developed for the dissemination of home garden agricultural technology as demonstrated at Taman Agro Inovasi BPTP Jawa Tengah.

Keywords: Learning Media, Adobe Flash CS6, Agriculture, Yard, BPTP Jawa Tengah. 


\begin{abstract}
Abstrak
Pemasyarakatan inovasi dan teknologi (inotek) pertanian di lahan pekarangan mendapat perhatian besar dari Kementerian Pertanian, dengan tujuan untuk meningkatkan produksi pangan dan akses masyarakat terhadap pangan, serta menjadi jaring pengaman sosial pada saat terjadi pandemi Covid-19. Sejak tahun 2017 BPTP Jawa Tengah telah mengembangkan Taman Agro Inovasi yang berisi display beragam inotek pertanian di pekarangan, untuk dijadikan sebagai tempat pembelajaran bagi penggiat maupun pelaku pertanian di pekarangan. Penelitian ini bertujuan untuk membuat multimedia interaktif untuk membantu penggiat dan calon pengguna dalam mempelajari inotek pertanian pekarangan yang didisplaykan di Taman Agro Inovasi tanpa harus berkunjung secara langsung di lokasi. Penelitian diawali dengan penggalian data dan informasi tentang inotek pertanian pekarangan yang didisplaykan di Taman Agro Inovasi, dilanjutkan dengan perancangan multimedia, pembuatan projek multimedia, validasi oleh pembimbing dan pakar, dan uji kelayakan multimedia. Berdasarkan hasil validasi dari ahli media, pakar materi dan sasaran pengguna menunjukkan bahwa produk multimedia yang dihasilkan sangat layak untuk digunakan dan dikembangkan untuk diseminasi inotek pertanian pekarangan sebagaimana yang diperagakan di Taman Agro Inovasi BPTP Jawa Tengah.
\end{abstract}

Kata kunci : Media Pembelajaran, Adobe Flash CS6, Pertanian, Pekarangan, BPTP Jawa Tengah.

\title{
1. PENDAHULUAN
}

Dalam kamus Merriam Webster Online Dictionary (2008), diseminasi secara etimology berasal dari bahasa Latin disseminatus yang mengandung makna to spread a broad dan to disperse throughout. Pengertian diseminasi tersebut sejalan dengan dissemination dalam kamus bahasa Inggris yang juga bermakna to spread atau to distribute (Hornby, 1974; Echols dan Shadily, 1997). Diseminasi adalah suatu kegiatan penyebaran informasi yang ditujukan kepada kelompok target atau individu agar mereka memperoleh informasi, timbul kesadaran, menerima, mengubah perilaku sasaran, dan akhirnya mereka mampu memanfaatkan informasi tersebut. Perubahan yang diharapkan dari kegiatan diseminasi adalah akan terjadi pada aspek kognitif (pengetahuan - P), afektif (sikap - S) dan psikomotorik (keterampilan - K). Perubahan tersebut menuju ke arah yang sesuai dengan konsep dan cara yang benar atau seharusnya. Diseminasi juga biasa disebut sebagai proses penyebaran inovasi yang direncanakan, diarahkan, dan dikelola. Sehingga terjadi saling tukar informasi dan akhirnya terjadi kesamaan pendapat tentang inovasi tersebut.

Salah satu pengertian dari diseminasi yang banyak dirujuk adalah batasan yang dibuat oleh Everett M. Rogers (1983), dia mengatakan: Dissemination (diffusion) is an interactive process with the help of which the participants create and deliver information to each other about an innovation in order to reach mutual understanding. Successful actions. Dissemination always consists of four recognizable and definable elements: innovation, dissemination channels, time, and the people and communities which form the social system of the dissemination process.

Dari batasan di atas menunjukkan bahwa diseminasi itu adalah suatu proses interaktif dalam penyampaian inovasi, yang pada akhirnya dapat merubah pola pikir dan tindakan orang yang terlibat. Dari pengertian ini menunjukkan bahwa diseminasi bukan kegiatan satu arah tetapi merupakan suatu interaksi, dan pada akhirnya tidak saja mempengaruhi pola pikir kelompok sasaran namun bisa jadi orang yang membawa inovasi itu sendiri.

Dalam proses diseminasi terdapat unsur-unsur penting yang menentukan keberhasilan dari proses itu sendiri, salah satunya adalah media yang digunakan. Media memiliki fungsi sebagai sarana untuk menyampaikan informasi dari narasumber kepada kelompok/individu sasaran, antara lain pengguna informasi dan penentu kebijakan. Multimedia menunjuk kepada seperangkat hardware maupun software yang digunakan dalam satu kesatuan untuk menyampaikan suatu objek berupa pesan informasi dari satu pihak ke pihak yang lain.

Diseminasi dapat digunakan dalam berbagai bidang sebagai penyampaian informasi instansi/lembaga terkait misalkan dalam sektor pertanian yang dikelola oleh Kementerian Pertanian. Sejak tahun 2012 diseminasi inovasi teknologi (inotek) pertanian pekarangan mendapat perhatian besar dari Kementerian Pertanian dengan berbagai pertimbangan, antara lain: 1). Pertumbuhan jumlah penduduk terus meningkat sehingga produksi pangan juga harus terus meningkat. Sementara itu luas dan kapasitas lahan yang secara

JURNAL ILMIAH KOMPUTER GRAFIS，Vol.14, No.1, Juli 2021, pp. 1 - 7 
konvensional menjadi tumpuhan produksi pangan terus mengalami penurunan. Upaya optimalisasi pemanfaatan lahan perlu dilakukan. Potensi lahan pekarangan baik di pedesaan maupun perkotaan masih belum dimanfaatkan secara optimal untuk produksi pangan; 2). Pemanfaatan pekarangan untuk produksi pangan selain meningkatkan produksi juga meningkatkan akses terhadap pangan bagi setiap rumah tangga yang melakukannya; dan 3), Pada tahun ini di saat pandemi Covid-19, dimana mobilitas masyarakat dibatasi, pemanfaatan pekarangan untuk produksi pangan dapat menjadi jaring pengaman sosial. Kementerian pertanian berupaya agar masyarakat yang dibatasi mobilitasnya (tinggal di rumah) tidak kekurangan pangan tetapi sebaliknya menjadi produktif untuk menghasilkan bahan pangan, baik untuk keluarga maupun masyarakat lingkungannya.

Salah satu lembaga yang mendapat amanah untuk melakukan diseminasi inotek pertanian pekarangan adalah Balai Pengkajian Teknologi Pertanian (BPTP) Jawa Tengah yang beralamat Jl.Soekarno-Hatta No.10, Km.26 Kecamatan Bergas, Kabupaten Semarang. BPTP Jawa Tengah adalah Unit Pelaksana Teknis (UPT) Badan Penelitian dan Pengembangan Pertanian (Balitbangtan) Kementerian Pertanian yang memiliki tugas pokok dan fungsi untuk menciptakan dan mendiseminasikan teknologi pertanian spesifik lokasi Jawa Tengah (Admin BPTP, 2015). Dalam rangka diseminasi inotek pertanian pekarangan, sejak tahun 2017 BPTP Jawa Tengah mengembangkan sebuah miniatur rumah pangan yang disebut Taman Agro Inovasi, yaitu peragaan/display teknologi pertanian pekarangan, mencakup teknologi budidaya tanaman secara langsung di tanah, budidaya tanaman menggunakan wadah media tanah, vertikultur dan hidroponik. Pengembangan Taman Agro Inovasi disertai dengan pengembangan layanan publik berupa: layanan kunjungan untuk studi banding, konsultasi dan pelatihan bagi penggiat dan pelaku pemanfaatan pekarangan untuk produksi pangan.

Sebelum pandemi covid-19 Taman Agro Inovasi telah menjalankan fungsinya sebagai media diseminasi pertanian pekarangan. Dalam hal ini diseminasi inotek dijalankan melalui pelayanan kunjungan ke Taman Agro Inovasi, dengan kata lain, proses diseminasi berjalan bila kelompok sasaran datang secara langsung di

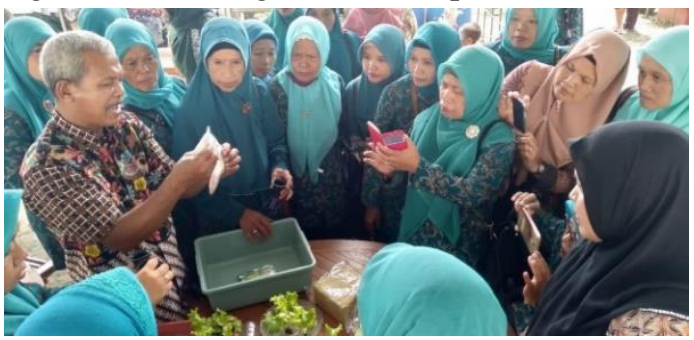

Gambar 1 Kunjungan PKK Boyolali Taman Agro Inovasi BPTP Jawa Tengah. Gambar 1 menunjukkan salah satu layanan kunjungan untuk Tim Penggerak PKK Desa Manyaran Kabupaten Boyolali ke Taman Agro Inovasi BPTP Jawa Tengah. Layanan kunjungan secara kelompok diawali dengan acara sambutan selamat datang di ruang pertemuan, yang diisi dengan penjelasan secara umum tentang peragaan inotek di Taman Agro Inovasi, dilanjutkan dengan tinjauan lapang (field trip) ke Taman Agro Inovasi disertai dengan penjelasan secara lebih rinci tentang inotek yang diperagakan oleh pemandu. Selain itu, Taman Agro Inovasi juga telah berkembang menjadi tempat pembelajaran pertanian bagi anak-anak usiadini, tempat pelaksanaan pelajaran luar sekolah (PLS) dan menjadi tempat praktek kerja lapang dan penelitian bagi pelajar dan mahasiswa (Sarjana, dkk. 2019). Gambar 2 menunjukkan kegiatan PLS siswa-siswi SD $\mathrm{N} \quad 4$ Gedanganak di Taman Agro Inovasi BPTP Jawa Tengah.

Walaupun demikian peranan dan manfaat Taman Agro Inovasi dalam mendukung diseminasi inotek pertanian pekarangan dinilai masih belum optimal karena berbaga masalah, yaitu: 1). Hanya sebagian kecil kelompok sasaran yang telah mengunjungi Taman Agro Inovasi BPTP Jawa Tengah; 2). Durasi kunjungan umumnya sangat terbatas sehingga pengunjung tidak bisa mempelajari inotek yang diperagakan di Taman

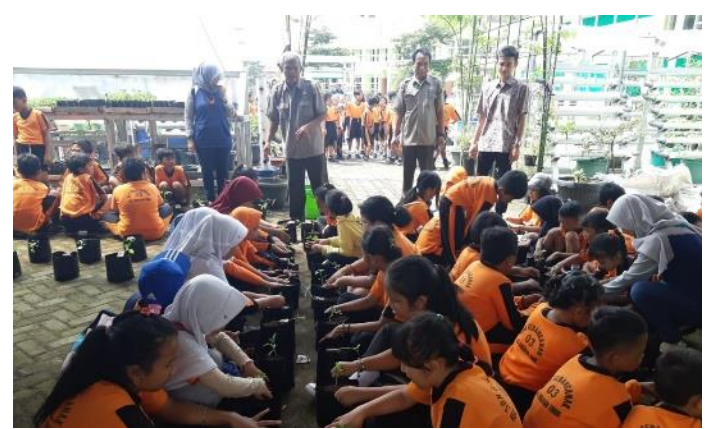

Gambar 2. Kunjungan PLS SD N 4 Gedanganak Agro Inovasi secara optimal; dan 3). Jumlah kunjungan ke Taman Agro Inovasi cenderung menurun sejak adanya pembatasan mobilitas masyarakat untuk pengendalian persebaran covid-19. Kondisi tersebut menjadi penghambat proses percepatan diseminasi inotek pertanian pekarangan yang diperagakan di Taman Agro Inovasi BPTP Jawa Tengah.

Salah satu solusi dari permasalahan tersebut adalah penggunaan media pembelajaran berbasis multimedia interaktif yang memungkinkan kelompok sasaran mempelajari inotek pertanian sebagaimana

PERANCANGAN MEDIA PEMBELAJARAN UNTUK DISEMINASI TEKNOLOGI PERTANIAN PEKARANGAN BERBASIS MULTIMEDIA INTERAKTIF DI BPTP JAWA TENGAH (Ahmad Zainudin) 
yang diperagakan di Taman Agro Inovasi tanpa harus mengunjungi secara langsung. Peneliti berharap dapat memberikan solusi permasalahan dalam diseminasi inotek pertanian pekarangan tersebut dengan memanfaatkan media pembelajaran berbasis multimedia interaktif. Dengan metode ini kelompok sasaran dapat berinteraksi dengan obyek/materi diseminasi, yaitu inotek pertanian pekarangan yang diperagakan di Taman Agro Inovasi BPTP Jawa Tengah tanpa harus mengunjungi secara langsung ke lokasi. Multimedia interaktif ini dilengkapi dengan audio visual sehingga fungsi indera pendengaran dan penglihatan kelompok sasaran dapat bekerja lebih optimal dalam mempelajari obyek/materi diseminasi. Selain itu, pemanfaatan multimedia interaktif tidak dibatasi ruang dan waktu, sehingga kelompok sasaran dapat mempelajari materi diseminasi kapan dan di mana saja, asal tersedia sarana pendukungnya. Media pembelajaran berbasis multimedia interaktif dapat dikemas dalam bentuk $C D$ atau flash disk untuk selanjutnya dibagikan kepada kelompok sasaran, utamanya penggiat dan trainer untuk selanjutnya digunakan untuk menyebarluaskan kepada pengguna akhir, yaitu pelaku pertanian pekarangan.

Berdasarkan uraian di atas peneliti mangusulkan judul penelitian: Perancangan Media Pembelajaran untuk Diseminasi Teknologi Pertanian Pekarangan Berbasis Multimedia Interaktif di BPTP Jawa Tengah.

\section{TINJAUAN PUSTAKA}

2.1. Deskripsi Teoritik

1) Multimedia

Menurut Robin dan Linda yang dikutip oleh Suyanto (2005) adalah alat peraga yang dapat menciptakan presentasi yang dinamis dan interaktif yang mengkombinasikan teks grafik, animasi, audio, dan gambar video. Lebih lanjut menurut Daryanto (2010) multimedia pembelajaran adalah aplikasi multimedia yang digunakan dalam proses pembelajaran, dengan kata lain untuk menyalurkan pesan (pengetahuan, keterampilan dan sikap) serta dapat merangsang pilihan, perasaan, perhatian.

\section{2) Komponen}

Multimedia terdiri dari beberapa objek di dalamnya. Sutopo (2003) mengemukakan objek-objek yang terdapat di dalam multimedia antara lain: teks, grafik, audio, animasi, dan interaktivitas.

\section{3) Multimedia Interaktif}

Multimedia terbagi menjadi dua kategori, yaitu multimedia linear dan multimedia interaktif. Multimedia linear adalah suatu multimedia yang tidak dilengkapi dengan alat pengontrol apapun yang dapat dioperasikan oleh pengguna. Contohnya adalah TV dan film. Sementara itu, multimedia interaktif adalah suatu multimedia yang dilengkapi dengan alat pengontrol yang dapat dioperasikan oleh pengguna sehingga pengguna dapat memilih apa yang dikehendaki untuk proses selanjutnya. Contohnya antara lain adalah media pembelajaran interaktif, aplikasi game, dan lain-lain (Sutopo, 2012).

4) Aplikasi

Menurut Jogiyanto (2001) aplikasi merupakan penerapan, menyimpan sesuatu hal, data, permasalahan, pekerjaan kedalam suatu sarana atau media yang dapat digunakan untuk menerapkan atau mengimplementasikan hal atau permasalahan yang ada sehingga berubah menjadi suatu bentuk yang baru tanpa menghilangkan nilai-nilai dasar dari hal data, permasalahan, pekerjaan itu sendiri. Sedangkan menurut Supriyanto (2005) Aplikasi adalah program yang memiliki aktivitas pemerosesan perintah yang diperlukan untuk melaksanakan permintaan pengguna dengan tujuan tertentu.

\section{5) Pertanian}

Menurut Mangunwijaya dan Sailah (2005), pertanian sebagai suatu subsistem dalam kehidupan manusia bertujuan untuk menghasilkan bahan nabati dan hewani dengan penggunaan sumber daya alam secara maksimal dalam rangka untuk mencapai kesejahteraan hidup manusia dan kelestarian daya dukung lingkungan. Sedangkan menurut Sari Mulyaningsih (2016), objek formal dari ilmu pertanian adalah budidaya reproduksi dalam focus pengolahan tanah, budidaya, pemeliharaan, pemungutan hasil dari budidaya, peningkatan mutu hasil panen, penanganan (pasca panen), pemasaran hasil.

6) Hidroponik

Dalam kajian bahasa, hidroponik berasal dari kata hydro yang berarti air dan ponos yang berarti kerja. Jadi, hidroponik memiliki pengertian secara bebas teknik bercocok tanam dengan menekankan pada pemenuhan kebutuhan nutrisi bagi tanaman, atau dalam pengertian sehari-hari bercocok tanam tanpa tanah. Dari pengertian ini terlihat bahwa munculnya teknik bertanam secara hidroponik diawali oleh semakin tingginya perhatian manusia akan pentingnya kebutuhan pupuk bagi tanaman. Di mana pun tumbuhnya sebuah tanaman akan tetap dapat tumbuh dengan baik apabila nutrisi (unsur hara) yang dibutuhkan selalu tercukupi. Dalam konteks ini fungsi dari tanah adalah untuk penyangga tanaman dan air yang ada merupakan

JURNAL ILMIAH KOMPUTER GRAFIS，Vol.14, No.1, Juli 2021, pp. 1 - 7 
pelarut nutrisi, untuk kemudian bisa diserap tanaman. Pola pikir inilah yang akhirnya melahirkan teknik bertanam dengan hidroponik, di mana yang ditekankan adalah pemenuhan kebutuhan nutrisi (Rini Rosliani dan Nani Sumarni, 2005).

\section{7) Akuaponik}

Rakocy et al. (2006) menyebutkan bahwa akuaponik adalah kombinasi akuakultur dan hidroponik yang bertujuan untuk memelihara ikan dan tanaman dalam satu sistem yang saling terhubung. Sistem akuaponik mereduksi amonia dengan menyerap air buangan budidaya atau air limbah dengan menggunakan akar tanaman yang berfungsi sebagai biofilter sehingga amonia yang terserap mengalami proses oksidasi dengan bantuan oksigen dan bakteri nitrifikasi, amonia diubah menjadi nitrat (Widyastuti, 2008). Menurut Nugroho \& Sutrisno (2008), kandungan amonia dapat direduksi oleh tanaman hingga $90 \%$ dari kadar yang ada, sehingga air tersebut masih layak digunakan kembali sebagai media pemeliharaan ikan. Pada sistem akuaponik semua nutrisi yang dibutuhkan oleh tanaman berasal dari limbah ikan. Menurut Sutanto (1998), kolam pemeliharaan ikan kaya akan humus dan sisa pakan yang banyak mengandung hara (N, P dan K). Air mengandung limbah organik yang mempunyai nilai sebagai sumber hara bagi tanaman baik dengan cara hidroponik atau media tanah (Triyatmo \& Probosunu, 1997). Namun, menurut Somerville et al (2014), meskipun limbah padat ikan mengandung hampir semua nutrisi yang dibutuhkan oleh tanaman, baik unsur makro maupun mikro, beberapa unsur nutrisi sangat terbatas jumlahnya seperti kalium (K), kalsium (Ca) dan besi $(\mathrm{Fe})$, sehingga dapat mengakibatkan terjadinya kekurangan nutrisi.

\subsection{KajjianPenelitian yang Relevan}

Tabel 1. Kajian Penelitian yang Relevan

\begin{tabular}{|c|c|c|c|}
\hline & Jurnal 1 & Jurnal 2 & Jurnal 3 \\
\hline Judul & $\begin{array}{l}\text { Pemanfaatan Aplikasi } \\
\text { Multimedia Sebagai } \\
\text { Sarana } \\
\text { Penyebarluasan } \\
\text { Informasi dan } \\
\text { Penyuluhan Pertanian }\end{array}$ & $\begin{array}{l}\text { Pembuatan Produk } \\
\text { Multimedia Sebagai } \\
\text { Media Informasi } \\
\text { Dan Dokumentasi } \\
\text { Pertanian Di Balai } \\
\text { Besar Pengkajian } \\
\text { Dan Pengembangan } \\
\text { Teknologi Pertanian }\end{array}$ & $\begin{array}{l}\text { Komik sebagai Media } \\
\text { Diseminasi } \\
\text { Inovasi Pertanian }\end{array}$ \\
\hline Penulis & Eko Nugroho & $\begin{array}{l}\text { Nita Qonitah Desy } \\
\text { Ayu Sari, Aep } \\
\text { Setiawan, Elya } \\
\text { Nurwullan }\end{array}$ & Rachmat Hendayana \\
\hline Diterbitkan & Agustus 2009 & Juni 2018 & Pebruari 2012 \\
\hline Hasil Penelitian & $\begin{array}{l}\text { Hasil penelitian } \\
\text { menghasilkan produk } \\
\text { berupa multimedia } \\
\text { tentang } \\
\text { menginformasikan } \\
\text { teknologi pertanian. }\end{array}$ & $\begin{array}{l}\text { Hasil penelitian } \\
\text { menghasilkan } \\
\text { sebuah produk } \\
\text { multimedia seperti } \\
\text { poster, video } \\
\text { tutorial, dan video } \\
\text { dokumentasi } \\
\text { kegiatan }\end{array}$ & $\begin{array}{l}\text { Hasil Penelitian } \\
\text { menghasilkan sebuah } \\
\text { media cetak yaitu Komik } \\
\text { sebagai peran memberikan } \\
\text { sebuah pembelajaran dan } \\
\text { informasi tentang inovasi } \\
\text { pertanian. }\end{array}$ \\
\hline Kelebihan & $\begin{array}{l}\text { Multimedia Interaktif } \\
\text { yang berbasis event } \\
\text { based stand alone dan } \\
\text { dilengkapi dengan } \\
\text { modul video tutorial. }\end{array}$ & $\begin{array}{l}\text { Penelitian } \\
\text { menghasilkan } \\
\text { sebuah produk } \\
\text { media cetak maupun } \\
\text { media visual. Jadi } \\
\text { masyarakat dapat } \\
\text { memilih dalam } \\
\text { belajar dapat } \\
\text { memilih dengan cara } \\
\text { membaca maupun }\end{array}$ & $\begin{array}{l}\text { Dalam Komik ini terdapat } \\
\text { informasi tentang inovasi } \\
\text { pertanian, disertai gamba } \\
\text { - gambar yang jelas dan } \\
\text { menarik memudahkan } \\
\text { bagi yang membaca untuk } \\
\text { memahami }\end{array}$ \\
\hline
\end{tabular}


hanya dengan

melihat.

\begin{tabular}{|c|c|c|c|}
\hline Kekurangan & - & - & - \\
\hline $\begin{array}{l}\text { Kesimpulan } \\
\text { Penulis }\end{array}$ & $\begin{array}{l}\text { Pemanfaatan aplikasi } \\
\text { multimedia sebagai } \\
\text { sarana penyebaran } \\
\text { informasi dan penyu- } \\
\text { luhan pertanian mem- } \\
\text { berikan gambaran } \\
\text { bagaimana multimedia } \\
\text { dapat dikembangkan } \\
\text { dengan berbagai } \\
\text { macam model untuk } \\
\text { memenuhi kebutuhan } \\
\text { masyarakat akan } \\
\text { informasi pertanian. }\end{array}$ & $\begin{array}{ll}\text { Pemanfaatan } & \text { Poster } \\
\text { sebagai } & \text { sarana } \\
\text { penyebaran } & \\
\text { informasi dan Video } \\
\text { tutorial memudahkan } \\
\text { penyuluhan } \\
\text { pertanian } \\
\text { memberikan } \\
\text { informasi kepada } \\
\text { masyarakat tentang } \\
\text { teknologi pertanian. }\end{array}$ & $\begin{array}{l}\text { Penelitian menghasilkan } \\
\text { produk yaitu Komik yang } \\
\text { memberikan sebuah } \\
\text { informasi dan } \\
\text { pembelajaran tentang } \\
\text { inovasi pertanian bagi } \\
\text { yang melihat, yang di } \\
\text { sertai dengan gambar - } \\
\text { gambar yang menariik. }\end{array}$ \\
\hline
\end{tabular}

\subsection{Kerangka Berfikir}

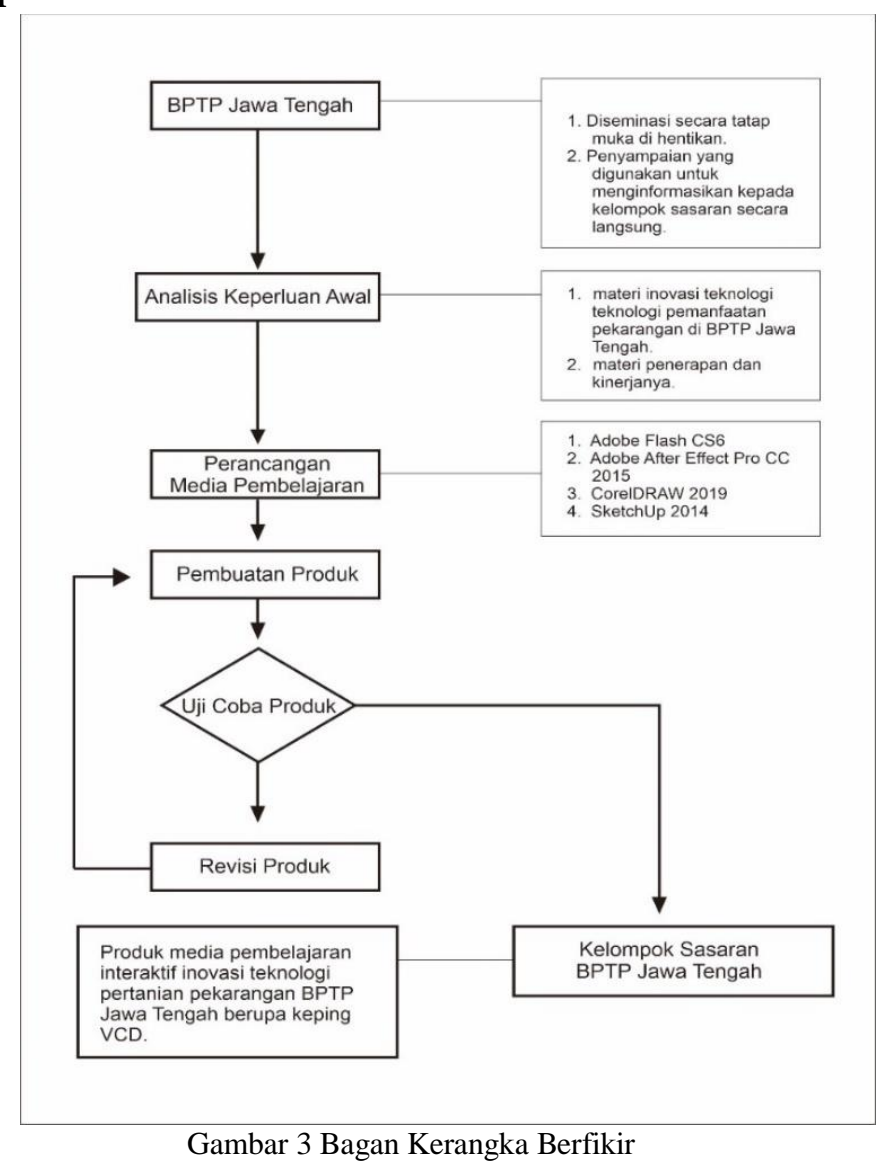

\subsection{Spesifikasi Produk yang Dikembangkan}

Produk yang dibuat merupakan media pembelajaran berbasis flash interaktif yang berisi tentang materi teknologi inovasi pertanian pekarangan yaitu hidroponik untuk penyuluh BPTP Jawa Tengah yang dapat digunakan kepada kelompok sasaran BPTP Jawa Tengah.

JURNAL ILMIAH KOMPUTER GRAFIS，Vol.14, No.1, Juli 2021, pp. 1 - 7 


\section{METODOLOGI PENELITIAN}

\subsection{Model Pengembangan}

Metode yang digunakan dalam penelitian ini adalah jenis penelitian dan pengembangan atau di kenal dengan istilah Research and Developmnent (R\&D). Metode penelitian merupakan rangkaian cara atau kegiatan pelaksanaan penelitian yang didasari oleh asumsi dasar, pandangan-pandangan filosofis, dan isu-isu yang dihadapi dalam penelitian. Metode penelitian dan pengembangan merupakan cara ilmiah untuk meneliti, merancang, memproduksi, dan menguji validitas produk yang dihasilkan (Sugiyono, 2015).

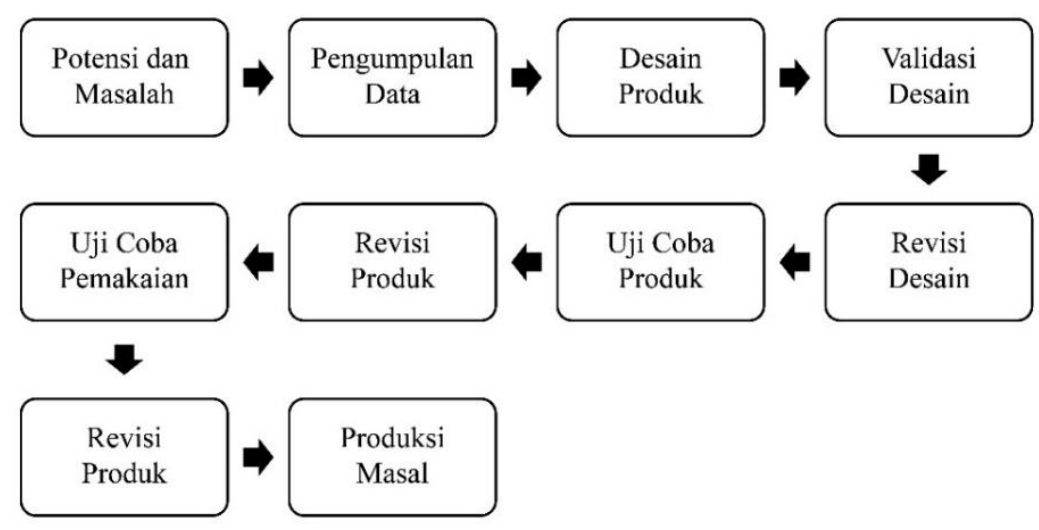

Gambar 4. Langkah-Langkah Metode R\&D

3.2 Prosedur Pengembangan

Penelitian ini, dari 10 langkah yang terdapat dalam metode R\&D hanya dipakai 6 langkah karena disesuaikan dengan kebutuhan penelitian pada tingkat pendidikan Strata 1 (S1). Prosedur pengembangan media informasi yang diadaptasi dari Borg \& Gall dilakukan dengan tahap-tahap sebagai berikut:

1) Tahap 1 Potensi dan Masalah

Berdasarkan latar belakang masalah yang ada dapat diidentifikasi permasalahan sebagai berikut:

a. Pengunjung taman agro inovasi cenderung merunun.

b. Peneliti BPTP Jawa Tengah masih menggunakan metode secara tatap muka dalam memberikan materi inovasi teknologi pertanian pekarangan.

c. BPTP Jawa Tengah membutuhkan media pembelajaran interaktif sebagai alat bantu pembelajaran.

2) Tahap 11 Pengumpulan dan Penelitian Data

Metode-metode yang digunakan penulis dalam mengumpulkan data adalah dengan cara dokumentasi data tertulis dan wawancara. Dokumentasi data tertulis dilakukan dengan cara dengan mencermati catatan dan dokumen yang menjadi pedoman dalam melakukan penelitian. Yang dilakukan penulis adalah mencermati data pengunjung taman agro inovasi. Sedangkan wawancara dilakukan dengan cara melakukan tanya jawab langsung kepada peneliti penanggung jawab taman agro inovasi BPTP Jawa Tengah.

3) Tahap 111 Desain Produk

Dalam hal pembuatan desain, penulis menyusun konsep media pembelajaran yang akan dibuat, media pembelajaran ini dirancang menggunakan software Adobe Flash CS6, untuk desain tampilan dan karakter menggunakan CorelDRAW 2019, dan untuk proses editing video menggunakan Adobe After Effect CC 2015.

4) Tahap IV Validasi Media Pembelajaran

Setelah tahap pembuatan desain produk selesai, dilanjutkan dengan validasi desain dan materi mengenai produk yang dirancang. Produk berupa media pembelajaran inovasi teknologi pertanian pekarangan khususnya budidaya hidroponik dan akuaonik. Proses ini dilakukan agar produk yang dikembangkan layak untuk digunakan dalam proses diseminasi. Validasi dilakukan oleh pakar ahli yang kompeten di bidangnya. 
5) Tahap V Revisi Media Pembelajaran

Setelah dilakukan uji kelayakan, jika masih ditemukan bagian-bagian yang belum sesuai, maka penulis perlu melakukan perbaikan sesuai arahan yang diberikan oleh pakar ahli saat tahap uji validasi.

6) Tahap Vl Uji Coba Produk

Penulis perlu melakukan uji coba lapangan guna menguji keefektifan media pembelajaran yang dirancang. Uji coba ini diberikan kepada penyuluh BPTP Jawa Tengah sebagai perwakilan. Uji coba ini di lakukan guna mengetahui kualitas produk yang di kembangkan, yang nantinya bisa di gunakan penyuluh BPTP Jawa Tengah kepada kelompok sasaran.

\section{HASIL DAN PEMBAHASAN}

\subsection{Desain}

1) Tampilan Halaman Utama

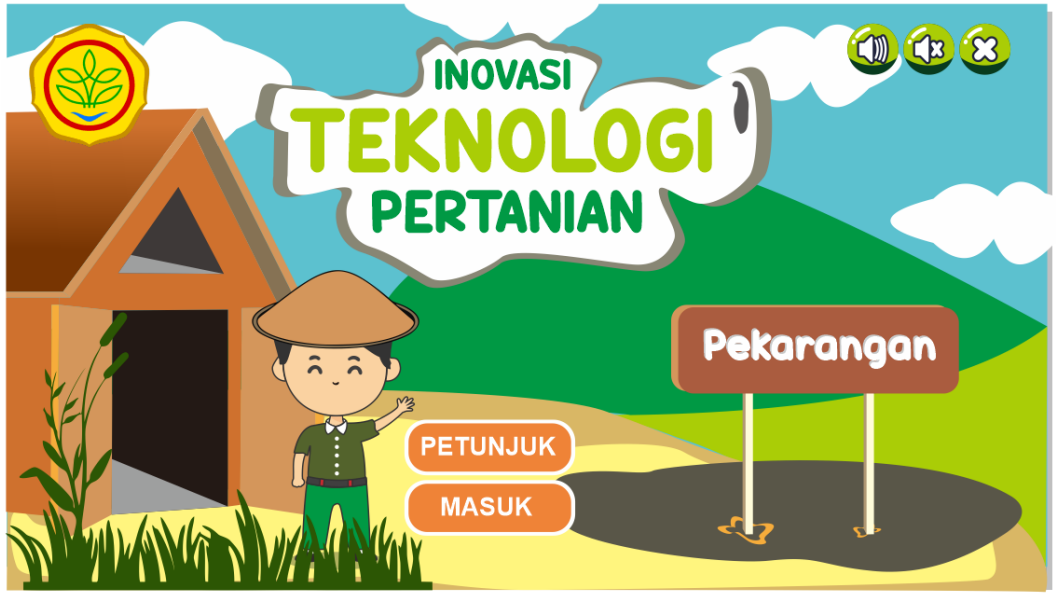

Gambar 5. Tampilan Halaman Utama

2) Tampilan Halaman Petunjuk

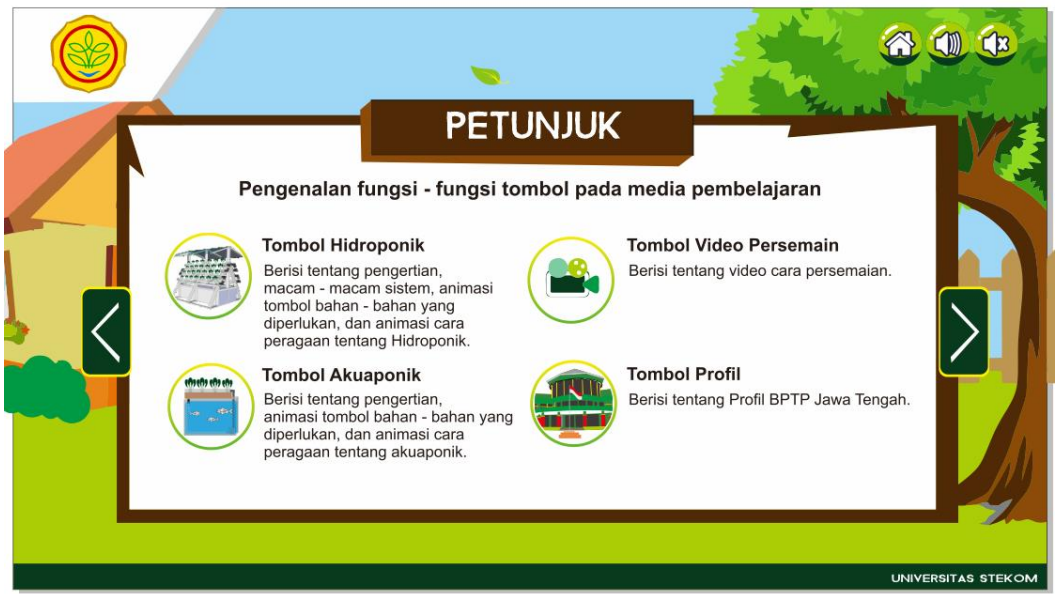

Gambar 6. Tampilan Halaman Petunjuk

3) Tampilan Halaman Menu Hidroponik

JURNAL ILMIAH KOMPUTER GRAFIS，Vol.14, No.1, Juli 2021, pp. 1 - 7 
9

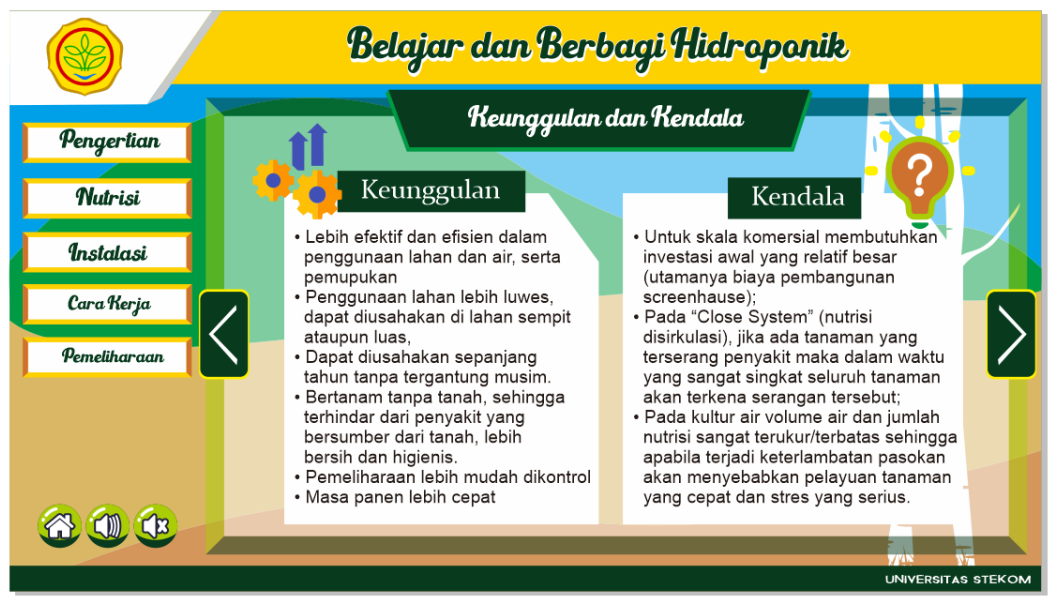

Gambar 7. Tampilan Halaman Menu Hidroponik

4) Tampilan Halaman Menu Akuaponik

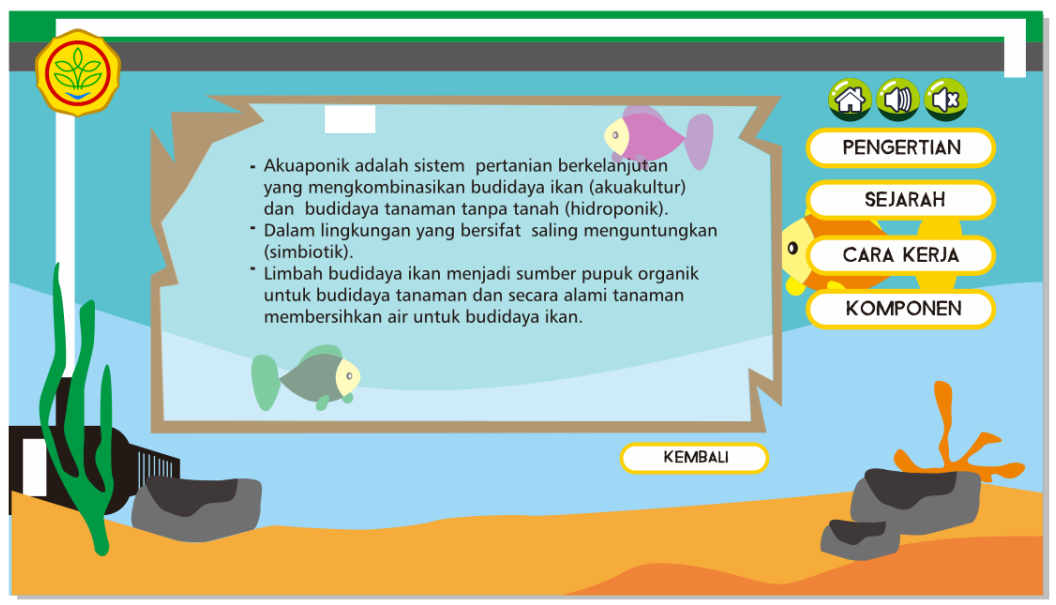

Gambar 8. Tampilan Halaman Menu Akuaponik

5) Tampilan Halaman Menu Video

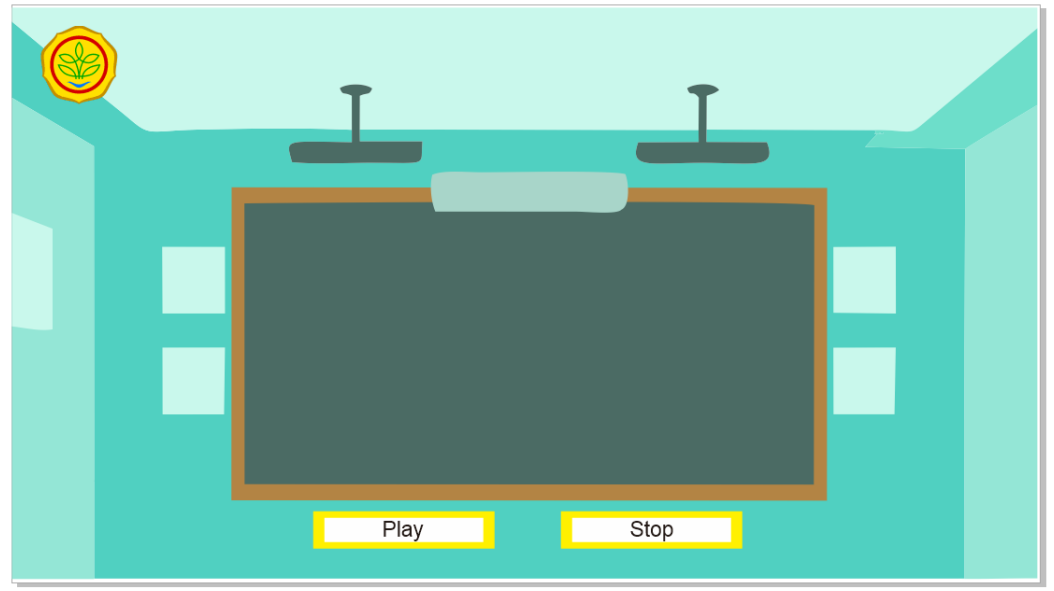

Gambar 9. Tampilan Halaman Menu Video 
6) Tampilan Halaman Profil

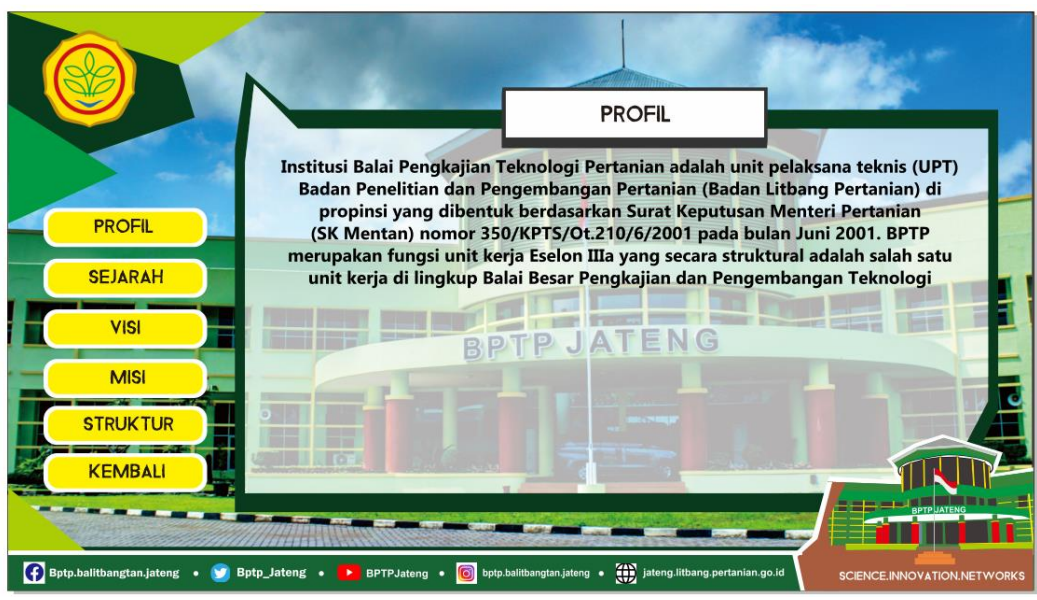

Gambar 10. Tampilan Halaman Menu Profil

7) Flow Chart

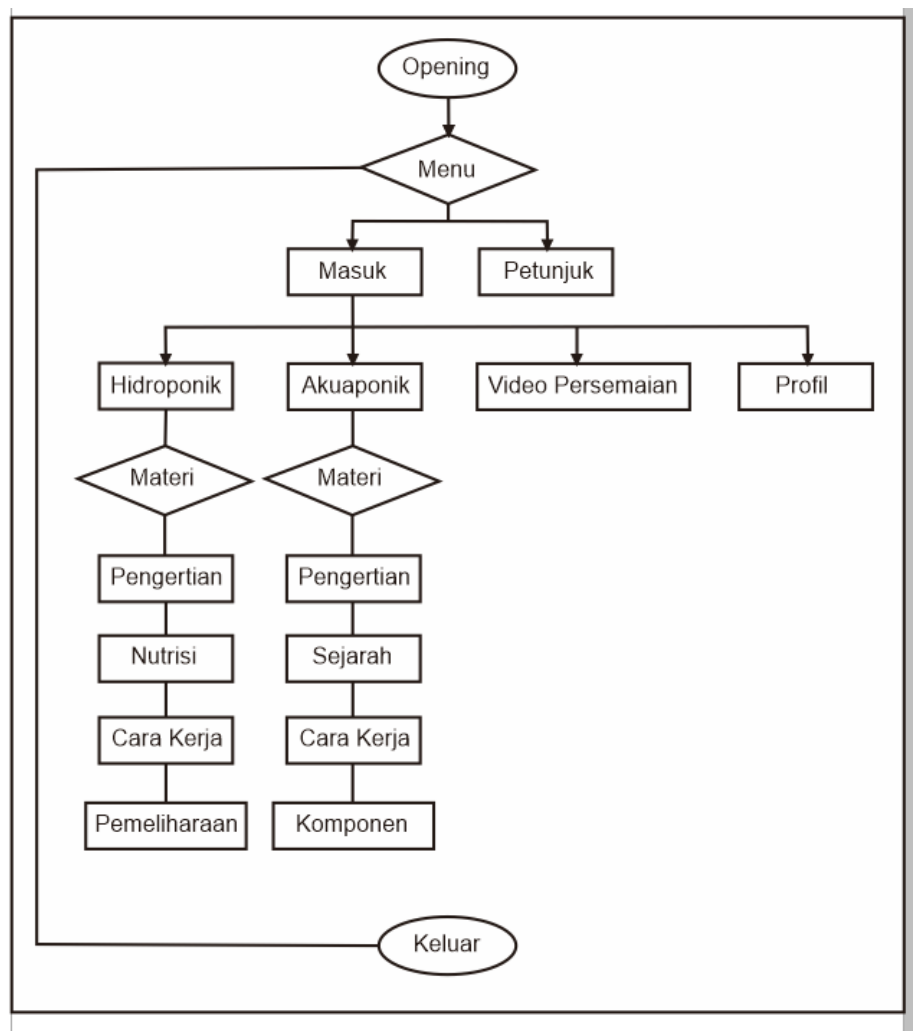

Gambar 11. Flow Chart Media Pembelajaran

JURNAL ILMIAH KOMPUTER GRAFIS，Vol.14, No.1, Juli 2021, pp. 1 - 7 
11

p-ISSN : 1979-0155 e-ISSN : 2614-8870.

\subsection{Hasil dan Pembahasan}

1) Hasil Validasi Media

Tabel 2. Hasil Validasi Media

\begin{tabular}{|l|l|l|l|c|c|}
\hline No & \multicolumn{1}{|c|}{ Indikator } & $\mathbf{1}$ & $\mathbf{2}$ & $\mathbf{3}$ & $\mathbf{4}$ \\
\hline $\mathbf{1}$ & Estetika tampilan awal pembuka & & & & $\checkmark$ \\
\hline $\mathbf{2}$ & Keterbacaan teks & & & $\checkmark$ & \\
\hline $\mathbf{3}$ & Fungsi tombol & & & & $\checkmark$ \\
\hline $\mathbf{4}$ & Pergerakan animasi & & & & $\checkmark$ \\
\hline $\mathbf{5}$ & Kesesuaian warna & & & & $\checkmark$ \\
\hline $\mathbf{6}$ & Kesesuaian tatak letak & & & & \\
\hline $\mathbf{7}$ & Kejelasan video peragaan & & & & $\checkmark$ \\
\hline $\mathbf{8}$ & Tampilan keseluruhan desain produk & & & 6 & 24 \\
\hline JUMLAH SKOR & & $\mathbf{3 0}$ & \\
\hline JUMLAH SKOR TOTAL & & & \\
\hline
\end{tabular}

Tabel 3. Keterangan

\begin{tabular}{|l|c|c|}
\hline \multicolumn{1}{|c|}{ Nilai } & Skor & Range \\
\hline & & \\
A (Sangat baik) & 4 & $25-32$ \\
B (Baik) & 3 & $17-24$ \\
C (Cukup) & 2 & $9-16$ \\
D (Tidak Baik) & 1 & $1-8$ \\
& & \\
\hline
\end{tabular}

Dari hasil pengujian melalui kuisioner yang berjumlah 8 indikator, nilai yang diperoleh adalah sebagai berikut:

$\begin{array}{lll}\text { A (sangat baik) } & : & 4 \times 6=24 \\ \text { B (baik) } & : & 3 \times 2=6 \\ \text { C (cukup baik) } & : & - \\ \text { D (kurang baik) } & : & - \\ \text { Total skor } & : & 30\end{array}$

Berdasarkan perhitungan di atas, diketahui bahwa hasil validasi media adalah 36 . Kriteria ini berada diantara 25 - 32, yaitu tergolong dalam kategori sangat baik. Sehingga media pembelajaran interaktif ini dapat dinyatakan valid dan layak untuk digunakan. 
2) Hasil Validasi Materi

Tabel 4. Hasil Validasi Materi

\begin{tabular}{|c|l|c|c|c|c|}
\hline No & Indikator & $\mathbf{1}$ & $\mathbf{2}$ & $\mathbf{3}$ & $\mathbf{4}$ \\
\hline $\mathbf{1}$ & Kesesuaian isi materi & & & $\checkmark$ & \\
\hline $\mathbf{2}$ & Menariknya media yang disajikan & & & & $\checkmark$ \\
\hline $\mathbf{3}$ & Kemudahan interaksi antarmuka & & & & $\checkmark$ \\
\hline $\mathbf{4}$ & Kemudahan memahami materi & & & & $\checkmark$ \\
\hline \multicolumn{2}{|c|}{ JUMLAH SKOR } & & 3 & 12 \\
\hline JUMLAH SKOR TOTAL & $\mathbf{1 5}$ \\
\hline
\end{tabular}

Tabel 5. Keterangan

\begin{tabular}{|l|c|c|}
\hline \multicolumn{1}{|c|}{ Nilai } & Skor & Range \\
\hline A (Sangat baik) & 4 & $13-16$ \\
B (Baik) & 3 & $9-12$ \\
C (Cukup) & 2 & $5-8$ \\
D (Tidak Baik) & 1 & $1-4$ \\
\hline
\end{tabular}

Dari hasil pengujian melalui kuisioner yang berjumlah 4 indikator, nilai yang diperoleh adalah sebagai berikut:
A (sangat baik)
$3 \times 4=12$
B (baik)
$3 \times 1=3$
C (cukup baik)
D (kurang baik)
Total skor
15

Berdasarkan perhitungan di atas, diketahui bahwa hasil validasi materi adalah 15 . Kriteria ini berada diantara 13 - 16, yaitu tergolong dalam kategori sangat baik. Sehingga media pembelajaran interaktif ini dapat dinyatakan sangat valid dan sangat layak untuk digunakan dengan adanya tambahan dan kelengkapan materi pada produk.

\section{3) Hasil Validasi Pengguna}

Tabel 6. Hasil Validasi Pengguna

\begin{tabular}{|c|l|c|c|c|c|}
\hline \multirow{2}{*}{ No Indikator } & \multicolumn{1}{|c|}{ Jumlah Pilihan Penyuluh } \\
& & \multicolumn{3}{c|}{ BPTP } \\
\cline { 2 - 5 } & & 1 & 2 & 3 & 4 \\
\hline $\mathbf{1}$ & Tampilan media pembelajaran menarik & - & - & 1 & 3 \\
\hline $\mathbf{2}$ & Tulisan dabat dibaca dengan jelas & - & - & - & 4 \\
\hline $\mathbf{3}$ & Gambar dan animasi menarik & - & - & 1 & 3 \\
\hline $\mathbf{4}$ & Penjelasan dalam media pembelajaran ini mudah dipahami & - & - & 1 & 3 \\
\hline $\mathbf{5}$ & $\begin{array}{l}\text { Dengan menggunakan media ini dapat mempermudah } \\
\text { menyampaikan materi }\end{array}$ & - & - & - & 4 \\
\hline $\mathbf{6}$ & $\begin{array}{l}\text { Layak untuk digunakan sebagai media dalam penyuluhan } \\
\text { teknologi pertanian }\end{array}$ & - & - & - & 4 \\
\hline $\mathbf{7}$ & Menambah pengetahuan inovasi teknologi pertanian & - & - & - & 4 \\
\hline $\mathbf{8}$ & Merangsang untuk memperaktekan & - & - & - & 4 \\
\hline \multicolumn{2}{|}{ JUMLAH SKOR } & $(1 \times 0)$ & $(2 \times 0)$ & $(3 \times 3)$ & $(4 \times 29)$ \\
\cline { 2 - 5 } & JUMLAH SKOR TOTAL & & $\mathbf{0}$ & $\mathbf{9}$ & $\mathbf{1 1 6}$ \\
\hline
\end{tabular}

JURNAL ILMIAH KOMPUTER GRAFIS，Vol.14, No.1, Juli 2021, pp. 1 - 7 
Tabel 7. Keterangan

\begin{tabular}{|l|c|c|}
\hline \multicolumn{1}{|c|}{ Nilai } & Skor & Range \\
\hline A (Sangat baik) & 4 & $25-32$ \\
B (Baik) & 3 & $17-24$ \\
C (Cukup) & 2 & $9-16$ \\
D (Tidak Baik) & 1 & $1-8$ \\
\hline
\end{tabular}

Berdasarkan data dari 4 penyuluh (responden) dengan 8 jumlah indikator, total skor yang diperoleh adalah 125, maka dapat dihitung rata-rata skor validasi penggunaan produk dengan cara sebagai berikut:

$\begin{array}{llc}\text { Skor Validasi } & = & \text { Total Skor } \\ & & \frac{125}{\text { Jumlah Responden }} \\ \text { Skor Validasi } & = & 31,25\end{array}$

Berdasarkan perhitungan di atas, diketahui bahwa hasil validasi penilaian dari 4 penyuluh (responden) adalah 31,25. Kriteria ini berada diantara 25 - 32 yakni tergolong dalam kategori sangat baik, sehingga media pembelajaran interaktif ini dapat dinyatakan valid dan layak untuk diseminasi inovasi teknologi pertanian pekarangan di BPTP Jawa Tengah.

\section{KESIMPULAN DAN SARAN}

\subsection{Simpulan Tentang Produk}

Hasil penelitian, perancangan dan pengujian terhadap produk media pembelajaran inovasi teknologi pertanian pekarangan yang dilakukan di BPTP Jawa Tengah, maka dapat disimpulkan sebagai berikut:

1) Produk yang dihasilkan dapat menjadi alat bantu belajar yang menarik karena telah mengkombinasikan unsur visual/gambar, animasi dan video yang di kemas menjadi satu dengan pemberian tombol-tombol navigasi sehingga menghasilkan media pembelajaran interaktif.

2) Dengan adanya media pembelajaran inovasi teknologi pertanian pekarangan ini dapat membantu kelompok sasaran untuk mempelajari dan menyebarluaskan inotek pertanian pekarangan, khususnya hidroponik dan aquaponik yang diperagakan di Taman Agro Inovasi BPTP Jawa Tengah.

3) Dengan hasil nilai validasi ahli media A (Sangat baik), ahli materi A (Sangat Baik), dan pengguna A (Sangat baik) maka produk media pembelajaran ini tergolong kategori sangat valid untuk digunakan.

\subsection{Saran}

Hasil penelitian dari perancangan media pembelajaran ini, terdapat beberapa saran kepada penulis, untuk penelitian selanjutnya agar dapat dikembangkan lebih baik lagi, yaitu:

1) Diharapkan untuk peneliti selanjutnya agar dapat menyajikan media pembelajaran dengan materi yang lebih luas dan lengkap.

2) Pengembangan selanjutnya diharapkan mampu menghadirkan media pembelajaran interaktif yang dapat diakses melalui smartphone, sehingga produk lebih praktis dan fleksibel untuk digunakan.

\section{DAFTAR PUSTAKA}

[1] Admin BPTP, 2015; “Tugas dan Fungsi”, Jawa Tengah: BPTP, [http://jateng.litbang.pertanian.go.id/].

[2] Daryanto, 2010; “Media Pembelajaran”, Yogyakarta: Gava Media. 
[3] Eko Nugroho, 2009; "Pemanfaatan Aplikasi Multimedia Sebagai Sarana Penyebarluasan Informasi dan Penyuluhan Pertanian", Bogor: Departemen Pertanian.

[4] Everett M, Rogers, 1983; "Diffusion of Innovations", London: The Free Press.

[5] Hornby, A.S. 1974; "Oxford Leaner's Dictionary of Current English”, Oxford: University Press.

[6] Jogiyanto, 2001; "Analisis \& Desain Sistem Informasi: pendekatan terstruktur teori dan praktek aplikasi bisnis", Yogyakarta: Andi.

[7] Lingga P, 2005; "Hidroponik Bercocok Tanam Tanpa Tanah", Jakarta: PenebarSwadaya.

[8] Kharolina Arifianti, 2020; "Perancangan Media Pembelajaran Matematika Materi Statistika Berbasis Flash", Semarang: Universitas Sains dan Teknologi Komputer.

[9] Mangunwijaya, Jumali dan Sailah, Illah, 2005; "Pengantar Teknologi Pertanian" Jakarta: Penebar Swadaya.

[10] Nita Qonitah Desy Ayu Sari, Aep Setiawan, Elya Nurwullan, 2018; "Pembuatan Produk Multimedia Sebagai Media Informasi Dan Dokumentasi Pertanian Di Balai Besar Pengkajian Dan Pengembangan Teknologi Pertanian", Bogor: Agricultural University.

[11] Nugroho E, \& Sutrisno, 2008; "Budidaya Ikan dan Sayuran dengan Sistem Akuaponik”, Jakarta: Penebar Swadaya $68 \mathrm{hlm}$.

[12] Omar A, S, Bin, 2012; "Dunia Ikan”, Yogyakarta: Gadjah Mada University Press.

[13] Rachmat Hendayana, 2012;"Komik sebagai Media Diseminasi Inovasi Pertanian", Bogor: BBP2TP Pertanian.

[14] Rakocy et.al, 2006; "Development of an Aquaponic System for the Intensive Production of Tilapia and Hydroponic Vegetables", University of the Virgin Island Agricultural Experiment Station: Kingshill, U.S Virgin Island.

[15] Rini Rosliani dan Nani Sumarni, 2005; "Budidaya Sayuran dengan System Hidroponik", Bandung: Monografi No. 27. Balai Penelitian Sayuran.

[16] Sarjana, 2019; "Laporan Tahunan Taman Agro Inovasi", Jawa Tengah: Balai Pengkajian Teknologi Pertanian Jawa Tengah

[17] Sari Mulyaningsih, 2016. "Kajian Penerapan Teknologi”, Agrobisnis: F Pertanian, Ump.

[18] Sugiyono, 2015; "Metode Penelitian Kuantitatif, Kualitatif dan R\&D”, Bandung: Alfabeta.

[19] Somerville et, al, 2014; "Small-scale aquaponic food production integrated fish and plan farming", Food and Agriculture Organization of the United Nations.

[20] Supriyanto, Aji, 2005; "Pengantar Sistem Informasi”, Yogyakarta: Salemba

[21] Sutanto R, 1998; "Inventarisasi teknologi alternatif dalam mendukung pertanian berkelanjutan", Yogyakarta: Fakultas Pertanian UGM.

[22] Sutopo, Ariesto Hadi, 2003; "Multimedia Interaktif dan Flash”, Yogyakarta: PT Graha Ilmu.

[23] Sutopo, Ariesto Hadi, 2012; “Teknologi Informasi dan Komunikasi dalam Pendidikan”, Yogyakarta: Graha Ilmu.

[24] Suyanto, 2005; "Multimedia Alat Untuk Meningkatkan Keunggulan Bersaing”, Jakarta: Andi.

JURNAL ILMIAH KOMPUTER GRAFIS, Vol.14, No.1, Juli 2021, pp. 1 - 7 
15

p-ISSN : 1979-0155 e-ISSN : 2614-8870

[25] Triyatmo B, \& Probosunu N, 1997; "Budidaya Lele Dumbo Bersama Tanaman Air", Yogyakarta: Fakultas Pertanian UGM.

[26] Widyastuti Y, R, 2008; "Peningkatan produksi air tawar melalui budidaya ikan sistem akuaponik", Bogor: Prosiding Seminar Nasional Limnologi IV LIPI. 62-73.

[27] Zeemry dan Harto, 2008; "Multimedia Sebagai Media Pembelajaran Interaktif", [http://www.maswins.com/2010/07/multimedia-sebagaimedia-pembelajaran.html / pada tanggal 22 Februari 2016 pukul 18.00 WIB. 